\title{
Rollover risk, network structure and systemic financial crises
}

\author{
Kartik Anand* \\ Prasanna Gai** \\ Matteo Marsili***
}

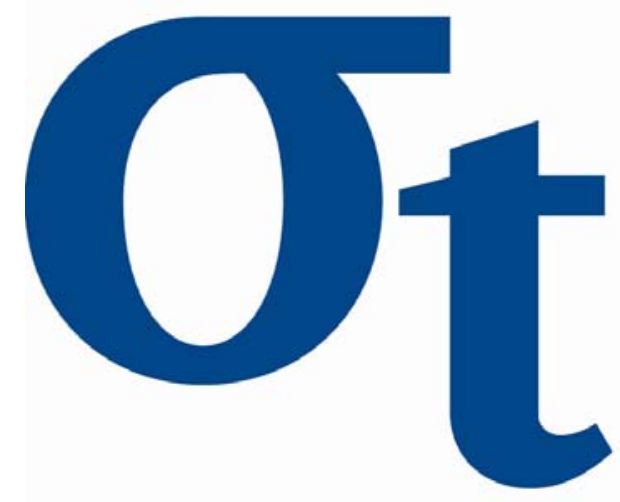

9)

寸

6

* Technische Universität Berlin, Germany

$* *$ University of Auckland, New Zealand

***Abdus Salam International Centre for Theoretical Physics, Italy

This research was supported by the Deutsche Forschungsgemeinschaft through the SFB 649 "Economic Risk".

http://sfb649. wiwi.hu-berlin.de ISSN 1860-5664 


\title{
Rollover risk, network structure and systemic financial crises
}

\author{
Kartik Anand ${ }^{*, a}$, Prasanna Gai $^{\mathrm{b}}$, Matteo Marsilic \\ ${ }^{a}$ Technische Universität Berlin, Sek. H 52, Straße des 17. Juni 135, 10623 Berlin, Germany \\ ${ }^{b}$ Department of Economics, University of Auckland, 12 Grafton Road, Auckland 1142, New Zealand \\ ${ }^{c}$ The Abdus Salam International Centre for Theoretical Physics, \\ Strada Costiera 11, 34014 Trieste, Italy
}

\begin{abstract}
The breakdown of short-term funding markets was a key feature of the global financial crisis of 2007/8. Combining insights from the literature on global games and network growth, we develop a simple model that sheds light on how network topology interacts with the funding structure of financial institutions to determine system-wide crises. We show how the arrival of bad news about a financial institution leads others to lose confidence in it and how this, in turn, spreads across the entire interbank network. The rate of system-wide bank failure is rendered endogenous, depending crucially on both the rate at which bad news arrives and on the maturity of debt contracts. The conditions under which the financial system makes a sharp transition from a dense network of credit relations to a sparse network where credit freezes readily occur are characterized. Our results also emphasize the role of hysteresis - once broken, credit relations take a long time to re-establish as a result of common knowledge of the equilibrium. Our findings shed light on the nature of public policy responses both during and after the crisis.
\end{abstract}

JEL classification: C72, G01, G21.

Key words: interbank networks, credit crisis, liquidity freeze 


\section{Introduction}

The global financial crisis of 2007/8 has highlighted the intertwined nature of financial systems. The emergence of financial instruments in the form of credit default swaps, collateralized debt obligations, and other credit derivative products vastly increased the connectivity between financial institutions worldwide. The heavy reliance of many of these institutions on short-term wholesale funding markets resulted, moreover, in a dramatic increase in rollover risk at a system level. What initially began as a localized difficulty in the US sub-prime mortgage market rapidly escalated beyond the United States - once some financial institutions were found to be in difficulty, investors became wary of lending to each other and interbank markets quickly froze, pushing many banks and other financial intermediaries into difficulty.

Figure 1 illustrates how the arrival of news of losses at troubled hedge funds, downgrades of structured financial products, and concerns about asset quality increased funding pressures on all banks. These changes was not gradual but abrupt and sharp. Before the crisis, banks required some 10 basis points of compensation for making one-month loans to each other. By September 2007, that compensation premium had risen to around 100 basis points. The ensuing collapse of the investment banks Bear Stearns and Lehman Brothers in 2008 resulted in the premium rising more than thirty-fold from pre-crisis levels. Notwithstanding the subsequent large-scale public sector bailouts of the banking system in many countries, it has taken over 12 months since the troubles at Lehman Brothers for this premium to return to pre-crisis levels. The compensation premium for three and six month loans followed a similar pattern, spiking after the collapse of Lehman Brothers. However, their return to pre-crisis levels has been more prolonged.

The global scale of the breakdown in the interbank markets has been without precedent and poses challenges for our understanding of systemic risk. The rollover decision of banks in short-term debt markets is typically modeled as a co-

\footnotetext{
${ }^{2}$ An earlier version of this paper was circulated under the title, Financial crises and the evaporation of trust. We are grateful to Christian Basteck, Hans Gersbach, Sujit Kapadia, Alan Kirman, Frank Heinemann, Priyanka Malhotra, Frank Milne, Thomas Lux and four anonymous referees for helpful comments and suggestions for improvement. The comments of participants at the International School and Conference on Network Science (Boston, 10-14 May, 2010), 6th World Congress of the Bachelier Finance Society (Toronto, 22-26 June, 2010), 10th World Congress of the Econometric Society (Shanghai, 17-21 August, 2010) and the Conference on Quantifying and Understanding Dysfunctions of Financial Markets (Leuven, 15-16 October, 2010), are also gratefully acknowledged.

KA acknowledges support of the Deutsche Forschungsgemeinschaft through the Collaborative Research Center (Sonderforschungsbereich) SFB 649 on "Economic Risks".

*Corresponding author; kartik.anand@tu-berlin.de.
} 
ordination game between lenders involved with a single, risky, counterparty. As Morris and Shin $(2003,2008)$ point out, when market participants have imperfect common knowledge of fundamentals, strategic uncertainty about the actions of other participants can be more important than structural uncertainty concerning the soundness of balance sheets. In such global games, the arrival of bad news about a debtor's balance sheet causes small seeds of doubt to reverberate across all lenders, leading potentially to a mass withdrawal of lending which forces the bank into early liquidation.

The recent crisis, however, is noticeable for the multiplicity of counterparties and overlapping groups of creditors. As Morris and Shin (2008) observe, banks such as Northern Rock in the UK were - ultimately - fishing from the same pool of short-term funding as investment banks such as Bear Stearns and BNP Paribas that were sponsoring off-balance sheet vehicles that used asset-backed commercial paper. As a result, banks participating in the interbank market were party to many coordination games at the same time. As lenders, they were involved in as many coordination games as counterparties to whom they had extended loans. And, as borrowers, they were also subject to coordination games being played by the creditors lending to them.

The analysis of the systemic consequences of rollover risk must, therefore, be able to 'scale up' the insights from global game models to the system level. Moreover, it must also take into account the dynamic nature of credit relationships - the short-term nature of unsecured funding in interbank markets is such that loans are continually maturing and being established between new, as well as existing, counterparties.

In an authoritative survey, Allen and Babus (2009) argue that viewing modern interbank markets as networks may offer insights for the breakdown of global funding markets in 2007/8. They hint at the consequences of a scaling up of global games, suggesting that small exogenous changes in investor risk and the arrival of adverse information may have system-wide consequences. They pose the possibility of an equilibrium with an empty network - one in which financial institutions are loathe to lend to each other. Bech and Atalay (2010) also suggest that interbank market can be viewed as a financial network in which banks are nodes and loans are directed links and note, moreover, that credit relations are established through a random matching process. Loans take place through an anonymous brokered market in which borrowers and lenders learn about each other only after a match is established at an agreed upon loan rate ${ }^{1}$.

In this paper, we build on these insights to better understand how funding ma-

\footnotetext{
${ }^{1}$ See also Pritsker (2009).
} 
turity and network structure interact to generate systemic financial crises. Specifically, we extend the insights of the game-theoretic analysis of coordination failure in debt markets to the system level using a model of network growth. In so doing, we provide a plausible account of the interbank credit freeze that characterized the global financial crisis of 2007/8. The model shows how the arrival of bad news about a financial institution can lead others to lose confidence in it and how this, in turn, spreads across the entire system. Our results also highlight the role of hysteresis - once rollover risk crystallizes and creditors take flight, credit relations between institutions can take a very long time to re-establish.

A crucial feature of our model is the rate at which bad news about the creditworthiness of a bank arrives. This, together with the maturity structure of debt contracts, determines the (endogenous) rate of link decay in the network. Intuitively, when bad news arrives an intermediary may be forced into default by the ensuing foreclosures. This leads to a rearrangement of balance sheets across the financial system - creditors who have lent to it lose assets, while intermediaries who borrowed from the defaulter lose liabilities. As a result, there is a possibility that some counterparties may be placed under stress, precipitating further rounds of foreclosures. We discuss the properties of the stationary state of these processes.

Our results may be summarized as follows. The financial system can converge to a "good" equilibrium in which a dense network of credit relations exists and the risk of a run, and subsequent default, is negligible. But a "bad" equilibrium is also possible - here the credit network is sparse because investors are more skittish and prone to prematurely foreclosing their credit relationships. The transition between the two equilibria is sharp. In the case that interbank loans have lengthy maturities in comparison to the rate at which bad arrives, both states exhibit a degree of resilience; once a crisis tips the system into the sparse state, the restoration of credit relations requires considerable effort, with model parameters needing to shift well beyond the turning point. And when the system reverts to a good state, it is robust even to deteriorating conditions.

\section{Related literature}

Our paper complements several recent studies of the global financial crisis. Allen et.al (2010) also consider the interaction between network structure and funding maturity. Their analysis explicitly takes optimal network formation and strategic behavior into account and suggests investor's rollover decisions depend on the structure of the network, investors' opportunity costs, and the magnitude of bankruptcy costs. But their analysis is static in nature and focuses on a network in which there are six banks. Caballero and Simsek (2009) also develop a model of a (small) financial network in order to study systemic risk. They appeal to the rising 
costs of understanding the structure of the network as the basis for complexity. If information about the network structure is costless, there is no foreclosure. But if, following a shock, these information costs rise sharply, banks' inability to understand the structure of the network to which they belong leads them to withdraw from their loan commitments ${ }^{2}$.

May et.al (2008), Haldane (2009) and Schweitzer et al. (2009) highlight the importance of developing models of financial system resilience using more general techniques and insights from the literature on networks and complex systems. Recent analyses in this vein include May and Arinaminpathy (2010), Gai and Kapadia (2010), and Gai et.al (2011). Although these models allow for an arbitrary number of financial institutions, the underlying topology of interactions and the balance sheets of the intermediaries are static. Moreover, strategic interactions are not taken into account ${ }^{3}$.

Finally, it should be noted that several recent studies consider the interbank freeze without recourse to network methods. Prominent among these is Acharya et al. (2011) who also highlight the role played by information arrival relative to rollover frequency. Their focus, however, is on the debt capacity of assets used as collateral for short-term borrowing. He and Xiong (2011) consider how rollover risk leads to bank runs in an explicitly dynamic game-theoretic setting involving a single borrower. Their model is characterized by coordination problems among creditors with debt contracts of random maturity. Brunnermeier and Oehmke (2010) develop a model of the equilibrium maturity structure for a financial institution that borrows from multiple creditors, while Diamond and Rajan (2011) show how liquidity risk can arise from the fear of asset firesales.

\section{The model}

Consider a population of $N \in \mathbb{N}$ risk-neutral financial institutions, "banks" for short, engaged in bilateral credit relationships with each other. A financial system of this kind can be viewed as a directed network, with nodes representing the financial institutions and outgoing links reflecting loans from one bank to another. The credit network is dynamic, with debt contracts (or links) continuously being established and terminated as they reach maturity. To keep matters simple, suppose

\footnotetext{
${ }^{2}$ See Allen and Babus (2009) for a review of models of financial crisis. The focus of analytical models involving a small number of banks follows in the seminal footsteps of Allen and Gale (2000) who model contagion in a four-bank system.

${ }^{3}$ Related work that draws on network techniques to explore contagion also includes Hatchett and Kühn (2009), Giesecke and Weber (2006), Nier et.al. (2007), and Afonso and Shin (2011). The latter use lattice-theoretic techniques to study systemic risk in high-value payment systems.
} 
that all loans take the same nominal value.

The financial position of bank $i$ at time $t \in \mathbb{R}^{+}$is summarized by the assets and liabilities on its balance sheet. Assets include holdings of liquid assets (cash), $b_{i}^{0} \in \mathbb{R}^{+}$, as well as loans made to other banks, $b_{i}^{(t)} \in \mathbb{N}$. Liabilities, namely the monies owed by bank $i$ to its counterparties, are denoted by $\ell_{i}^{(t)} \in \mathbb{N}$ and reflect the number of incoming links. The level of assets and liabilities are related to each other via the adjacency matrix $A^{(t)} \in\{0,1\}^{N x N}$. The matrix element $a_{i j}^{(t)}$ denotes whether at time $t$ bank $i$ holds an asset against bank $j$ or not. Thus, the assets and liabilities of bank $i$ are

$$
b_{i}^{(t)}=\sum_{j=1}^{N} a_{i j}^{(t)}, \quad \text { and } \quad \ell_{i}^{(t)}=\sum_{j=1}^{N} a_{j i}^{(t)} .
$$

Since every liability is someone else's asset, every outgoing link for one node is an incoming link for another node. So the total amount of assets in the system matches the total liabilities at all times, or equivalently, the average in-degree equals the average out-degree $\left\langle b^{(t)}\right\rangle=\left\langle\ell^{(t)}\right\rangle$, where the angled bracket refers to the average over all banks. That said, individual banks may be in surplus or deficit in their individual financial positions. The average connectivity, $\rho^{(t)}=\left\langle\ell^{(t)}\right\rangle$ of the network offers a summary measure of the extent of global financial market integration in what follows.

The dynamic evolution of the network is punctuated by time $t_{v}$-episodes where the $\ell_{i}^{\left(t_{v}\right)}$ lenders of bank $i$ engage in a game to decide whether to prematurely foreclose their loans to $i$. We first describe this foreclosure game, before clarifying the dynamics of the network.

\subsection{Foreclosure game}

At a time $t_{v}$, the creditors of bank $i$ receive adverse information about $i$ 's future profits and viability. At this time, bank $i$ has $\ell_{i}$ liabilities, $b_{i}$ interbank assets, and $b_{i}^{0}$ holdings of cash. The adverse information becomes common knowledge to all $\ell_{i}$ creditors, who must decide whether to withdraw their funds (foreclose), thereby minimizing losses were $i$ to fail, or roll over to maturity. Following Morris and Shin $(1998,2008)$, we model this decision by a binary action, simultaneous move game involving $\ell_{i}$-players (creditors) in an incomplete information setting. To keep notation concise, we drop the time $t_{v}$ index from the balance sheet variables for the remainder of this section.

For each creditor $j$, foreclosure yields a payoff of zero, whereas rolling over yields a payoff of $1-c_{j}>0$, provided that the number of lenders who opt out does not exceed $b_{i}+b_{i}^{0}$, on the asset side of bank $i$ 's balance sheet. If, however, more than $b_{i}+b_{i}^{0}$ financial institutions opt out, this depletes the financial resources of bank 
$i$, who is forced into default. This results in lender $j$, who decided to roll over, to incur a loss of $c_{j} \in \mathbb{R}$. Following Morris and Shin (2008), we refer to $c_{j}$ as the cost of miscoordination to $j$. The cost of miscoordination reflects the opportunity cost to creditor $j$ of rolling over the loan and being confronted with little liquidation value, instead of investing in an alternative (safe) asset such as government bonds. It is also a measure of the difficulty of achieving coordination in practice - when $c_{j}$ is high, coordination may be difficult to achieve because creditors are doubtful whether others will roll over their loans to the borrower.

The payoff matrix for creditor $j$, in terms of the number $\ell_{i}^{\prime}$ of creditors other than $j$ who roll over, is therefore

\begin{tabular}{c|c|c} 
& $\ell_{i}^{\prime} \geq b_{i}+b_{i}^{0}-1$ & $\ell_{i}^{\prime}<b_{i}+b_{i}^{0}-1$ \\
\hline foreclose & 0 & 0 \\
\hline roll over & $1-c_{j}$ & $-c_{j}$
\end{tabular}

where the payoff to rolling over a loan is increasing in the number of lenders who roll over their loans. As the global games literature makes clear, with common knowledge of payoffs we have a tri-partite classification of costs. For $c_{j}<0$ the benefits from rolling over the loan always outweigh foreclosure and hence rolling over is the dominant pure strategy equilibrium. On the other hand when $c_{j}>1$ the converse is true and foreclosure is dominant. Finally, for $c_{j} \in[0,1]$ there are multiple equilibria.

\subsubsection{Unique equilibrium of the foreclosure game}

Suppose that $c_{j}$ is a random variable drawn from an arbitrary distribution that is common to all banks ${ }^{4}$. The properties of binary action, simultaneous move global games with a finite number of players have been investigated by Morris and Shin (2003) and Frankel et al. (2003). These papers demonstrate via the iterative deletion of dominated strategies that the unique surviving Bayes-Nash equilibrium is a "threshold-strategy," which is noise independent.

Here, we follow Morris and Shin (2003) and suppose that banks have Laplacian beliefs about the costs faced by other creditors. This implies that a bank who is indifferent between actions believes that the fraction of other counterparties who roll over their loans is an uniformly distributed random variable with support $\left\{0,1 /\left(\ell_{i}-1\right), 2 /\left(\ell_{i}-1\right), \ldots, 1\right\}$. We exploit this simplification for the exposition of our equilibrium solution.

\footnotetext{
${ }^{4}$ This relaxes the assumption of common knowledge of payoffs as the cost $c_{j}$ is private to bank $j$.
} 
Theorem 1. The unique equilibrium for the foreclosure game, under Laplacian beliefs, amounts to all $\ell_{i}$ counterparties of bank $i$ utilizing the threshold-strategy

$$
\left\{\begin{array}{lll}
\text { rollover } & \text { if } & c_{j} \leq c^{\star} \\
\text { foreclose } & \text { if } & c_{j}>c^{\star}
\end{array} \text { with } c^{\star} \equiv \frac{b_{i}+b_{i}^{0}}{\ell_{i}}\right.
$$

Formally, the critical $c^{\star}$ is also a function of time $t_{v}$, since $b_{i}$ and $\ell_{i}$ are dynamic variables. However, to keep notation concise we drop the time index for $c^{\star}$ in this section. A heuristic proof for Theorem 1 is provided in Appendix A.

Theorem 1 offers a simple and intuitive explanation for rollover risk, where $c^{\star}$ is an asset-to-liability ratio, which measures whether bank $i$ has sufficient resources to meet its obligations. When $c^{\star}$ is large, bank $i$ has a surplus of assets. The costs of miscoordination faced by the creditors of $i$ will typically be less than $c^{\star}$, thereby facilitating coordination between creditors and resulting in the rollover of loans. On the other hand, when $c^{\star}$ is small, the converse is true - bank $i$ typically has too large a debt to service with its current assets. In this case, creditors are likely to panic and foreclose against bank $i$, thereby precipitating bankruptcy.

The noise independence of this result implies that strategic uncertainty is relevant even in the absence of uncertainty on the costs of other players. In what follows, given our emphasis on the collective behavior of the network, we assume $c_{j}=c$ for all banks $j$, irrespective of the counterparty. To simplify matters further, we also treat the liquid asset holdings of banks, $b_{i}^{0}$ to be constant across the network so that $b_{i}^{0}=b^{0}$ for all banks.

\subsection{Network dynamics}

We now represent the dynamical evolution of our interbank network using a random matching framework. The formation of a debt contract between any two banks is a random draw from all possible contracts between banks in the network. At all times, the state of the interbank network is fully specified by the adjacency matrix $A^{(t)}$, whose elements $a_{i j}^{(t)}$ are now cast as stochastic variables. Consequently, the balance sheet random variables for liabilities $\ell_{i}^{(t)}$, and assets $b_{i}^{(t)}$, are governed by continuous time Poisson processes ${ }^{5}$.

At time $t$ and with rate $\gamma>0$, each bank $i$ takes out a loan from bank $j$, selected at random from the pool of other financial institutions. With the contractual link between the banks established, the variable $a_{i j}^{(t)}$ is set to one. The parameter $\gamma$ can be viewed as a proxy for the balance sheet growth of financial intermediaries.

\footnotetext{
${ }^{5} \mathrm{~A}$ Poisson process is defined with rate $\alpha$ if for every infinitesimal interval $[t, t+\tau)$ an event occurs independently and with probability $\alpha \tau$. In our case, the probability that a new loan is issued from bank $i$ to $j$ in time interval $[t, t+\tau)$ is $\gamma \tau$.
} 
As Adrian and Shin (2010) emphasize, banks typically expand their balance sheets rapidly when macroeconomic conditions are benign. On the liability side they take on more short-term debt, while on the asset side they search for potential borrowers to lend to in an effort to deploy surplus capital ${ }^{6}$. Our choice in modeling the creation of loans and addition of links by stochastic processes subsumes behavioral considerations. We do not explicitly model the reasons behind why a bank seeks a short-term loans, but rather consider them to be driven by exogenous factors. This allows us to concentrate on the systemic rollover risk.

Each existing loan matures at rate $\lambda>0$ and is amicably settled by counterparties. This results in the termination of the link between banks, i.e., $a_{i, j}^{(t)}$ is set to zero. When $\lambda$ is small, debtors in the interbank market are typically investing their loans in long-term projects.

At random Poisson times $t_{v}$, which occur with rate $v>0$, the creditors of bank $i$ receive an adverse information about $i$ 's future losses. This information, which may reach creditors either by way of official public disclosures or rumors, has the effect of forcing creditors to question whether they should continue lending to bank $i$ or withdraw their loans. The decision rule is given by the foreclosure game where the amount of assets and liabilities

$$
b_{i}^{\left(t_{\nu}\right)}=\sum_{j} a_{i, j}^{\left(t_{\nu}\right)}, \quad \text { and } \quad \ell_{i}^{\left(t_{\nu}\right)}=\sum_{j} a_{j, i}^{\left(t_{v}\right)},
$$

on bank $i$ 's balance sheet, are made common knowledge to the creditors. There is collective foreclosure by all creditors on bank $i$ if

$$
c \ell_{i}^{\left(t_{\nu}\right)}>b_{i}^{\left(t_{\nu}\right)}+b^{0} .
$$

As a consequence, bank $i$ is said to default and is replaced by a new bank with no links, i.e. entries $a_{i, j}$ and $a_{j, i}$ are set to zero, for all $j=1, \ldots, N$. This implies that financial institutions, $j$, who previous borrowed from $i$ will each lose one liability. Likewise, the banks, $k$, who lent to $i$ will each lose one asset ${ }^{7}$. If, instead, Eq. (5) is not satisfied, then all of $i$ 's counterparties will rollover their loans, and the foreclosure game will have no effect.

These dynamics are conveniently represented in terms of the liabilities, $\ell_{i}^{(t)}$ and assets, $b_{i}^{(t)}$ of each bank. Indeed, a bank's financial state at time $t$ is specified in terms of its position $\left(\ell_{i}^{(t)}, b_{i}^{(t)}\right)$ in the balance sheet plane. Figure 2 depicts the three

\footnotetext{
${ }^{6}$ Indeed, during the subprime crisis, balance sheets expanded so quickly and the urge to employ surplus capital was so great that lenders extended credit to extremely poor quality borrowers.

${ }^{7}$ Such assets and liabilities may be settled on longer time horizons, which we disregard for the sake of simplicity.
} 
processes, (i) link addition at rate $\gamma$ per bank, (ii) link decay at rate $\lambda$ and (iii) the arrival of adverse signals at rate $v$ per bank, in the $(\ell, b)$ plane.

In specifying the stochastic processes we have further assumed that the rates $\gamma$, $\lambda$ and $v$ are the same for all financial institutions. This simplifies our analysis and allows us to focus on the balance sheet of a typical financial institution.

\section{Results}

We now turn to the properties of the stationary state of these processes. For simplicity and without loss of generality, we set $\gamma=1$ in what follows, by an appropriate scaling of the unit of time $\tau$. We first establish that a stationary state exists.

By definition, the evolution of the interbank network, which is governed by a series of Poisson processes, may be succinctly described by a Markov process ${ }^{8}$ where:

Proposition 1. For any finite population size $N$, the interbank network Markov process is ergodic and possesses a unique invariant measure (stationary state).

The proof for proposition 1 is provided in Appendix B. Furthermore, in Appendix $\mathrm{D}$ we establish limiting case results for the stationary state in terms of the network density and endogenous rate of bank failure. We first prove that for $c=0$ and $b^{0}>0$, the credit network is a random graph, with network density $1 / \lambda$ in the large $N$ limit. Second, in the limits $N \rightarrow \infty, \lambda \rightarrow 0$ and for all $c<1$, a dense network without any collective foreclosures is always a solution to the stationary state.

The picture that emerges is as follows. For small $c$ and $\lambda$, a "good" state, which is default free and has a dense network can be attained. However, for $c=1$ and irrespective of how small $\lambda$ is made, the process is plagued by a "bad" state where defaults are persistent. In what follows, we probe the nature of this transition between good and bad extremes by resorting to a series of approximate schemes and numerical simulations.

\subsection{Master equation}

The processes for the evolution of the interbank network can be described by a master equation (see Gardiner (2009)) for the probability distribution function $P_{t}(A)$ that at time $t$ we observe the interbank network $A^{(t)}=A$. This distribution

\footnotetext{
${ }^{8}$ The probability for a bank to have balance sheet position $\left(\ell_{i}^{(t+\tau)}, b_{i}^{(t+\tau)}\right)$ depends on the bank's position at time $t$, i.e., $\left(\ell_{i}^{(t)}, b_{i}^{(t)}\right)$.
} 
function includes the joint probability of balance sheet positions $\left(\ell_{i}^{(t)}, b_{i}^{(t)}\right)$ for all banks.

A simpler equation can be written for the marginal distribution function $P_{t}(\ell, b)$ of the fraction of banks with $\ell_{i}^{(t)}=\ell$ liabilities and $b_{i}^{(t)}=b$ assets ${ }^{9}$. The master equation in this case takes the following form:

$$
\begin{aligned}
\partial_{t} P_{t}(\ell, b) & =\mu \delta_{\ell, 0} \delta_{b, 0}+\gamma P_{t}(\ell-1, b)+\gamma P_{t}(\ell, b-1) \\
& +\left(\lambda+\mu_{b}\right)(\ell+1) P_{t}(\ell+1, b)+\left(\lambda+\mu_{l}\right)(b+1) P_{t}(\ell, b+1) \\
& -\left[v \Theta\left(c \ell-b-b^{0}\right)+2 \gamma+\left(\lambda+\mu_{b}\right) \ell+\left(\lambda+\mu_{\ell}\right) b\right] P_{t}(\ell, b),
\end{aligned}
$$

where $\partial_{t}$ is the partial derivative with respect to time and $\Theta(\ldots)$ refers to the Heaviside function ${ }^{10}$.

The rates $\mu, \mu_{l}$ and $\mu_{b}$ are endogenous default rates, which are self-consistently determined against the stationary distribution ${ }^{11}$ of $(\ell, b)$ as

$$
\begin{aligned}
\mu & =v \sum_{\ell, b} \Theta\left(c \ell-b-b^{0}\right) P(\ell, b), \\
\mu_{\ell} & =\frac{v}{\langle\ell\rangle} \sum_{\ell, b} \Theta\left(c \ell-b-b^{0}\right) \ell P(\ell, b), \\
\mu_{b} & =\frac{v}{\langle b\rangle} \sum_{\ell, b} \Theta\left(c \ell-b-b^{0}\right) b P(\ell, b) .
\end{aligned}
$$

Here, $\langle b\rangle$ and $\langle\ell\rangle$ are the mean assets and liabilities, respectively. The angled brackets refers to the average over $P(\ell, b)$, which in fact yields $\langle b\rangle=\langle\ell\rangle$.

We can understand the master equation via simple geometric considerations using Fig. 2. Let us focus on an arbitrary point $(\ell, b)$ in the interior of the lattice. The probability that a bank has this balance sheet position at time $t$ is given by the probability that the bank was on a neighboring sites at time $t-\tau$, where $\tau \ll 1$, and made an incremental hop to $(\ell, b)$. If the bank was previously to the left or bottom of $(\ell, b)$ then the hop would have been achieved by the bank gaining a new asset or liability, both of occur at rate $\gamma$.

${ }^{9}$ This approach corresponds to a mean field approximation which assumes that the joint probability of the position of two banks $i$ and $j$ can be factorized $P_{t}\left(\ell_{i}, b_{i} ; \ell_{j}, b_{j}\right) \cong P_{t}\left(\ell_{i}, b_{i}\right) P_{t}\left(\ell_{j}, b_{j}\right)$. This approach would be exact were it not for the foreclosure game process, which couples the balance sheets of different banks. Nevertheless, the fact that loans are formed through a random matching process provides justification for this approach.

${ }^{10}$ Specifically, $\Theta(x)=1$ if and only if $x \geq 0$ and otherwise $\Theta(x)=0$.

${ }^{11}$ Independent of time- $t$ sub-script. 
The rate at which a hop occurs from either above or the right is simply the rate at which either an asset or liability are lost, respectively. In the latter case, this rate may be decomposed into two aspects: (i) the natural dissipation of a link, i.e., $\lambda$ and (ii) the probability that the bank was a creditor to another bank who defaulted from collective foreclosure with rate $v$. The rate at which such incidents occur is $\mu_{b}$. A similar argument may be used to construct the rate at which assets are lost. Whenever a bank defaults it is stripped of all its assets and replaced by a new bank, who starts at $(\ell, b)=(0,0)$. The first term in Equation (6) reflects this action.

We may probe the collective properties of the stationary state either via direct numerical simulation of the processes or by solving Eq. (6) numerically.

\subsection{Network density}

In Fig. 3 we plot results from both numerical simulation and the solution to the master equation for the average connectivity $\rho$, once the system has reached a stationary state, as a function of the cost of miscoordination, $c$, for different values of debt maturity $\lambda$. We note the following features ${ }^{12}$. Firstly, for small $c$, there is a dense network and $\rho=1 / \lambda$. Although adverse signals about a bank permeate through the network, the costs of coordination failure are not sufficiently high to dissuade creditors from rolling over their loans. Secondly, for large $c$, the costs of miscoordination are high. Creditors are more jittery and sensitive to the asset-liability ratios of debtors. If this ratio decreases - with a lowering of liquid assets, for example - this has a knock-on effect for other institutions, who with worse asset-liability ratios are foreclosed upon themselves. This domino of foreclosures results in a sparse financial network outcome where credit relations between institutions are limited.

For small $\lambda$, i.e., when debt is long-lived and in an intermediate range of $c$, we note the coexistence of both dense and sparse network solutions ${ }^{13}$. Finally for larger $\lambda$, one morphs continuously from a dense network to a sparse one, as $c$ is increased.

The hysteresis observed for intermediate $c$ in Fig. 3 has a subtle interpretation. Far from the tipping point, a small incremental change in the opportunity $\operatorname{cost} c$

\footnotetext{
${ }^{12}$ The agreement between numerical simulations and the solution to the master equation is remarkably good, which substantiates our use of the mean field approximation.

${ }^{13}$ Coexistence of two different stationary states, which are attained depending on initial conditions, seemingly contradicts Proposition 1, which asserts that the stationary state is unique for all finite $N$. However, this is only an apparent contradiction, as transitions between the two states occur on time-scales that are exponentially large in $N$. Even for a moderately large value of $N$ the required transition time is well beyond the reach of numerical simulations. Furthermore, the Master equation corresponds to an approach where the limit $N \rightarrow \infty$ is taken before the limit $t \rightarrow \infty$. See Ehrhardt and Marsili (2006) for other systems where such ergodicity breaking is observed.
} 
(for given ratio $v / \lambda$ between the rates of news arrival and loan maturity) to roll over loans does not impact the decisions of banks to rollover loans to debtors. With a smaller $c$, creditors are more relaxed and less sensitive to changes in the asset-liability ratios for all other financial institutions. In particular, each creditor will argue that all other creditors will also follow the same switching strategy and since everyone has a low opportunity cost - common knowledge of the equilibrium - no one will foreclose. As a result we continue to observe the dense network outcome. Once the opportunity cost increases beyond the tipping point, a sparse network solution emerges via the domino of foreclosures. A bank's tolerance to adverse news and changes in assets-liabilities ratio is much reduced. Moreover, by the same incremental change argument, as one decreases $c$, the sparse network outcome is persistent. Each bank knows that all others follow the same switching strategy and have high opportunity costs. Thus, there is greater reluctance and an inertia against rolling over loans. The opportunity cost must decrease to well before the tipping point to regain the dense network solution.

\subsection{Endogenous rate of bank failure}

A qualitative understanding of our results is readily available via a simple approximation of the Poisson processes. The key variable is the endogenous rate of bank failure, $\mu$, due by collective foreclosures. Thus, $\mu$ depends on the rate $v$ at which adverse information propagates through the network and the maturity $\lambda$ of debt contracts. We show that for intermediate values of $c$ and $\lambda$, the endogenous rate of link decay $\mu$ has two solutions; one where bank failures are rare $(\mu \simeq 0)$ and the other where failures due to collective foreclosure is frequent $(\mu>0)$.

To derive an expression for $\mu$, we focus on the twin stochastic processes $\left(\ell^{(t)}, b^{(t)}\right)$ for the liability and asset positions of a typical bank. This process starts from the origin $\left(\ell^{(0)}, b^{(0)}\right)=(0,0)$ of Fig. 2 and drifts toward the top right-hand corner.

From any given point on the grid, jumps to the right and up occur at rate $\gamma=1$, whereas jumps to the left or below take place at rate $\lambda+\mu$. In the absence of the foreclosure game being played $(v=0)$, both processes converge to a stationary state, where $\ell^{(t)}$ and $b^{(t)}$ are Poisson variables with mean $1 /(\lambda+\mu)$. However, when $v$ is "turned on", the bank fails when $b^{(t)}+b^{0}<c \ell^{(t)}$, and restarts at the origin.

The endogenous rate of failure $\mu$ is given by the solution to the self-consistent equation

$$
\mu=\frac{v}{2} \operatorname{erfc}(Z)
$$


where $\operatorname{erfc}(\cdot)$ is the complimentary error function ${ }^{14}$ and

$$
Z=\frac{c-1+b^{0}(\lambda+\mu)}{\sqrt{2\left(1+c^{2}\right)(\lambda+\mu)}}
$$

The derivation of this result is provided in Appendix C. A graphical solution to Eq. (8) is provided in the inset of Fig. 4, where we have either one or three fixed points. Fig. 4 plots boundaries for regions in the $c$ vs. $\lambda$ plane where these different situations arise. In the dense (D) and sparse (S) phases, one obtains the stable fixed points $\mu \simeq 0$ and $\mu>0$, respectively.

When $\mu \simeq 0$ the failure of banks is very rare. Creditors are more likely to rollover loans when they play the foreclosure game. Their actions feed and influence the rollover actions of other financial institutions when they play the foreclosure game. This setting is conducive to a dense interbank market with rare instances of collective foreclosure. For $\mu>0$, which we observe for larger values of $c$, the situation is more dire. While playing the foreclosure game, creditors perceive their debtor's assets-liabilities ratio is too low, which leads to the debtor's default. The ensuing restructuring of balance sheets lowers the assets-liabilities ratios of other banks, leading to a wave of other foreclosures and defaults, resulting in a sparse network at the stationary state.

In the co-existence (CO) phase, however, the two stable solutions are separated by a third, unstable fixed point. If we impose initial conditions that placed the system to the left of the unstable solution, we would obtain the dense credit network solution with $\mu \simeq 0$. Similarly, starting just to the right of the unstable point would yield the sparse network solution $\mu>0^{15}$.

While precise numerical values of the transition points are not accurately reproduced within this simple approximation, the qualitative features are, however, clear. Increasing the level of liquid assets $b^{0}$, or decreasing the cost $c$, the curve in the inset of Fig. 4 moves to the right, thus favoring the dense network $(\mu \simeq 0)$. Likewise, decreasing $v$ flattens the function, suggesting that the coexistence of solutions is possible only for large values of $v$. This is indeed confirmed by numerical simulations. Finally, notice that the dependence on $\lambda$ only enters in the combination $\lambda+\mu$. Hence lowering debt maturity (increasing $\lambda$ ) is equivalent to shifting the

\footnotetext{
${ }^{14}$ The error function is $\operatorname{erf}(z)=\frac{2}{\sqrt{\pi}} \int_{0}^{z} e^{-t^{2}} \mathrm{~d} t$ and the complimentary error function is simply $\operatorname{ercf}(z)=1-\operatorname{erf}(z)$.

${ }^{15}$ Inspection of the argument $Z$ of the erfc function provides further insight. For small values of both $c$ and $\lambda$, only one solution with small $\mu \sim e^{-(1-c) /(2 \lambda)}$ is possible, as $Z$ is of order $1 / \sqrt{\lambda}$. For small $\lambda$ and $c \simeq 1$, instead, the term $1-c$ is negligible with respect to the term $b^{0}(\lambda+\mu)$. The argument of the erfc function is $Z \simeq b^{0} \sqrt{\lambda+\mu} / 2$ and Eq. (8), again, admits one unique solution. In the intermediate range, both solutions are possible, together with a third unstable one.
} 
whole curve to the left which again results in the disappearance of the coexistence region, as shown in Fig. 4 and in the simulations.

\section{Some policy implications of the model}

Our model and results help clarify both the public policy response at the time of the global financial crisis and the subsequent debate over reforms to the financial system. We consider each in turn.

\subsection{Policies introduced during the crisis}

The breakdown of short-term funding markets elicited a large-scale expansion of central bank balance sheets as major central banks such as the Bank of England, the European Central Bank, and the Federal Reserve stepped up the provision of liquidity insurance to the banking system. This attempt to shore up breaks in the private sector credit chain has been considerable. As Haldane (2009) notes, central bank balance sheets in the major economies are at historical highs, having doubled in size since the onset of crisis.

Central bank provision of liquidity insurance has, in most instances, taken the form of operations both on- and off-balance sheet. Central banks in the major economies initially responded to the crisis with on-balance sheet liquidity insurance measures, using open market operations involving extended definitions of collateral to provide the banks with the liquidity services they needed. The range of acceptable collateral was gradually widened from AAA rated securities to covered bonds and residential mortgage-backed securities. These open market operations began towards the end of 2007, expanded substantially during the autumn of 2008, and (in the case of the UK) peaked in early 2009. Off-balance sheet liquidity insurance facilities that allowed banks to swap relatively high quality assets for government bonds were also initiated in 2008. In the UK, for example, the Bank of England introduced a Special Liquidity Scheme (SLS) in April 2008 (see Cross et.al (2010)). The scheme remains in operation and is scheduled to terminate in 2012, almost five years after the start of the problems in the interbank market.

Our analytical framework offers clues to why such attempts to normalize funding market conditions may have been so protracted. The provision of public sector liquidity insurance has the effect of lowering the costs of miscoordination, $c$, in the model. With common knowledge of these opportunity costs, each bank knows that others also face lower opportunity costs and so are inclined to roll over loans. As Figure 3 suggests, however, following a crisis or "tipping point", these opportunity costs have to decline substantially for normal funding to resume. In the language of our network model, hysteresis effects dictate the ease with which the network moves from the sparse to the dense solution. Moreover, the extent of the hysteresis 
effect depends on debt maturity. For moderately short term debt $(\lambda=0.01)$, the model implies that resumption of normal market conditions requires a change in the miscoordination cost of 0.05 . By contrast, for longer term debt $(\lambda=0.005)$, the persistence is pronounced and the change in $c$ needed to restore a dense financial network is substantially higher (0.13). And in the case of very short-term debt $(\lambda=0.02)$, the network continuously morphs from the sparse to the dense network, suggesting that normal operations in funding markets might resume relatively quickly and involve relatively small reductions in the cost of miscoordination.

The flavor of these findings is borne out by Figure 1. Although we cannot properly calibrate either $\lambda$ or $c$ to real world data, Figure 1 illustrates how the length of time needed for compensation premia to return to their pre-crisis levels (i.e. to the level prior to Sept 2007) is increasing with loan maturity. The chart shows the cost of borrowing on 1, 3 and 6 month interbank loans, which we can loosely compare with the three levels of lambda depicted in Figure 3. Following the collapse of Lehman Brothers in September 2008, one month interbank loans returned to near-normal levels relatively quickly, i.e., by the start of 2009 . The costs of borrowing in the 3 and 6 month interbank markets, however, remained above pre-crisis levels for much longer, and were still significantly higher than 1 month rates in May 2009. The total time needed for compensation premia to return to their pre-crisis level in each of the 1,3 , and 6 month markets appears to be around 21,25 and 28 months respectively.

\subsection{The debate on financial sector reform}

At the heart of the systemic collapses modeled in our paper is a network externality: banks do not internalize the consequences of their foreclosure decisions on others in the network. The scale of the externality depends both on network structure as well as the composition of financial intermediary balance sheets. Our results allow consideration of policy measures along a range of dimensions, namely tougher liquidity regulation, greater transparency, systemic surcharges on liquidity (and capital), and structural changes to the network through the creation of central counterparties.

1. Tougher liquidity requirements: Our model reinforces the case for strong liquidity requirements advanced by Morris and Shin (2008). At the systemwide level, our results and simulations suggest that increasing liquid assets $\left(b^{0}\right)$ for all agents (for a given debt maturity, $\lambda$ ), results in dense credit networks with $\rho=1 / \lambda$ for large values of $c$. At the individual level, increasing $b_{i}^{0}$ clearly motivates creditor $j$ to rollover loans to agent $i$. The more substantial the liquid asset holdings of the borrowing bank, the more able it is 
to meet withdrawals. Moreover, stronger liquidity requirements for creditor banks lower the costs of miscoordination, since they would be less vulnerable to runs themselves. Liquid creditor banks tend to be less jittery and, hence, less trigger-happy.

The current policy debate (see Caruana (2009); Tucker (2009)) on promoting systemic financial stability emphasizes the importance of liquidity cushions in averting future crises. The Squam Lake Working Group on Financial Regulation (2009) also advocates setting liquidity requirements to be proportional to short-term debt. In our model, this amounts to setting $b_{i}^{0}=\beta_{i}+\alpha \ell_{i}$, where $\alpha$ is some pre-defined ratio. From Eq. 3, this is equivalent to reducing the costs of miscoordination $c$ to $c-\alpha$, and replacing $b_{i}^{0}$ by $\beta_{i}-\alpha$. Clearly, the benefits of ex post regulations of this kind need to be set against thee ex ante cost to banks of such regulation. That said, international regulators are moving ahead in this direction, seeking to define liquid assets as narrowly as possible in the spirit of the analysis developed here.

2. Transparency: Our model shows non-trivial effects from transparency policy as reflected by the public signal parameter, $v$, which has the effect of modulating the transition between dense and sparse states from sharp and abrupt to smooth and continuous. In particular, hysteresis is present only for large $v$, when the transition between states is sharp. Our model suggests that during a crisis, when the costs of miscoordination are likely to be high, interbank markets frozen and central banks have introduced measures to restore normal market activity, the recovery may be improved by reducing disclosure requirements, which is modeled as a reduction in $v$.

This action would allow problem banks (i.e. those in the shaded region of Figure 2) time to escape the danger zone by reorganizing their balance sheets with the addition of new (perhaps-state owned) assets and the retirement of some liabilities. Second, it has the twin effect of alleviating hysteresis, which reduces the level of effort that the central banks would otherwise have to employ, and also smoothing out the transition back to the dense interbank network. More generally, there seems to be a case for more careful analysis of adaptive disclosure requirements in the broader discussion on macro-prudential regulation ${ }^{16}$.

3. Systemic surcharges: As an alternative to blanket leverage ratios and liq-

\footnotetext{
${ }^{16}$ It is important to note, however, that our model neglects other important informational considerations such as moral hazard. Allowing for such issues may well change assessments of how transparency and disclosure policy affects systemic risk.
} 
uidity requirements, one option (see Gai et.al (2011)), is to levy liquidity charges or impose exposure limits on institutions in line with their contribution to overall systemic risk. The imposition of such a Pigovian tax regime has clear parallels with the work of Albert et al. (2000) on attacks on internet-router networks. In principle, our model can be extended to allow for differential link formation, $\gamma$, or preferential linakage where agents in one sub-group prefer to interact with others in the same sub-group. Agent heterogeneity of this kind holds the promise of new insights into the design of financial stability.

4. Central counterparties: A further regulatory initiative has been the drive to centrally clear over-the-counter financial products through central counterparties. In terms of the model, a central counterparty simplifies the network of bilateral exposures, with the central counterparties as hubs with unimpeachable balance sheets and banks holding assets and liabilities against these hubs. This setup arguably lowers strategic uncertainties between banks and replaces it with more measurable structural uncertainties against the central counterparties. A full investigation of structural changes to the network such as this is beyond the scope of the analysis in our paper, but it seems plausible to suppose that such policy measures should simplify the interaction between network structure and funding maturity, reducing systemic risk in the process.

\section{Conclusion}

We have attempted to clarify how network topology interacts with the funding structure of financial institutions to determine system-wide crises. The endogenous rate of system-wide bank failure depends on the arrival of bad news about a financial institution as well as on the maturity structure of interbank debt contracts. We are able to characterize the conditions under which funding markets "freeze" and highlight how the re-establishment of normal credit conditions in these markets can take a prolonged time as a result of common knowledge of the equilibrium. The model helps shed light on the breakdown of the interbank markets during the financial crisis and provides an analytical lens with which to view both the extraordinary policy measures taken by central banks during the crisis and the policy debate on post-crisis financial sector reform. Our contribution is also technical - we are able to show how global game techniques can be scaled up to the system level.

It is worth stressing that the model presented here is simple and is intended as a first step in understanding financial interactions in a network context. In particular, we do not allow for any macroeconomic variability and the key parameters of 
the model are, in reality, likely to be endogenous. The history of crises suggests that financial institutions are unlikely to be passive and sit idle whilst a sequence of defaults unfolds. For example, in a crisis, a counter-party may strategically disclose information or form links in ways that improves their chances of a public sector bailout, or positions them to capture market share at the expense of rivals in distress. Incorporating a richer set of economic interactions into a network setting such as ours is an important step for future research.

\section{A. Proof of theorem 1}

Assume all counterparties are subject to switching strategies, i.e., $j=1 \ldots, \ell_{i}$ will rollover its' loan, if $c_{j} \leq c^{\star}$, or foreclose, otherwise. Suppose creditor $h$ has $c_{h}=c^{\star}$. The creditor is indifferent between rolling over and foreclosing the loan. Evaluating the expected payoff for $h$, we get $\phi=c^{\star}$, where

$$
\phi=\mathbb{P}\left(\ell_{i}^{\prime} \geq b_{i}+b_{i}^{0}-1 \mid c_{h}=c^{\star}\right)
$$

is the probability that at least $b_{i}+b_{i}^{0}-1$ other creditors have cost less than $c^{\star}-$ and hence roll over their loans to $i$. To evaluate $\phi$ we use the Laplacian beliefs held by $h$ that $\ell_{i}^{\prime}$ is an uniformly distributed random variable over the integers $0,1,2, \ldots \ell_{i}-1$. This consequently implies that $\phi=\left(b_{i}+b_{i}^{0}\right) / \ell_{i}$ and hence yields the switching threshold result of Eq. (3).

\section{B. Proof of proposition 1}

We need to show that any state $\hat{A}$ can be reached from any state $\hat{A}^{\prime}$ by a sequence of elementary processes of link decay and addition. One such path is the one where all links in $\hat{A}^{\prime}$ first decay, and then all links in the state $\hat{A}$ are created. This process occurs with positive probability for all $\hat{A}$ and $\hat{A}^{\prime}$, hence the Markov chain is ergodic, and it possesses a unique invariant measure.

\section{Derivation for the endogenous rate of link decay}

We can formally express the endogenous rate of bank failure as

$$
\mu=v \mathbb{P}\left(b^{(t)}-c \ell^{(t)} \leq-b^{0}\right) .
$$

We can approximate $z=b^{(t)}-c \ell^{(t)}$ by a Normal distributed random variable with mean $(1-c) /(\lambda+\mu)$ and variance $\left(1+c^{2}\right) /(\lambda+\mu)$. This yields

$$
\mu=v \frac{\sqrt{\lambda+\mu}}{\sqrt{2 \pi\left(c^{2}+1\right)}} \int_{b^{0}}^{\infty} \exp \left(-\frac{1}{2}\left(z-\frac{1-c}{\lambda+\mu}\right)^{2} \frac{\lambda+\mu}{1+c^{2}}\right) \mathrm{d} z=\frac{v}{2} \operatorname{erfc}(Z),
$$

where $Z$ is defined in Eq. (9). 


\section{Limiting case results for the stationary state}

Our quantities of interest in the stationary state are the endogenous rate of bank failure

$$
\mu=v \sum_{\ell=0}^{\infty} \sum_{b<c \ell-b^{0}} P(\ell, b),
$$

and on the density (average degree) of the interbank network

$$
\rho=\sum_{\ell=0}^{\infty} \sum_{b=0}^{\infty} \ell P(\ell, b)
$$

where $P(\ell, b)$ is the fraction of banks with $\ell_{i}=\ell$ and $b_{i}=b$, in the stationary state.

When $v=0$ each loan is independently present or absent from all others. The same applies to the case where $c=0$ with $b^{0}>0$.

Proposition 2. For $c=0$ and $b^{0}>0$ the rate of default is $\mu=0$ and the credit network is described by a random graph where

$$
P(A)=\prod_{i \neq j} \frac{[\lambda(N-1)]^{1-a_{i j}}}{1+\lambda(N-1)},
$$

i.e., each loan between two banks is present, independently of all other loans, with probability $1 /[1+\lambda(N-1)]$.

Proof. With $c=0$ and $b^{0}>0$, defaults never occur because $b_{i}+b_{0}-c \ell_{i}>0$. Hence the process reduces to that with $v=0$. In this process, each loan $\left(a_{i j}=1\right)$ is present independent from all others and is described by a simple process for its generation and maturity, with rates $w\left(a_{i j}: 0 \rightarrow 1\right)=1 /(N-1)$ and $w\left(a_{i j}: 1 \rightarrow 0\right)=\lambda$, respectively. The stationary state of this process is evidently the one stated in the proposition.

With $b_{i}$ assets and $\ell_{i}$ liabilities for bank $i$, the Bernoulli distribution with $N-1$ trials and probability of success $1 /[1+\lambda(N-1)]$ is well approximated by a Poisson distribution with average $1 / \lambda$, for large $N$.

Proposition 3. In the limit of infinite population size $(N \rightarrow \infty)$ and $\lambda \rightarrow 0$, for $c<1$, the process admits a solution with $\mu=0$.

Proof. Let us assume that all banks apart from $i$ have a default rate equal to zero. We must show that $\mu=0$ also holds for bank $i$. In the limit $\lambda \rightarrow 0$ the dynamics of bank $i$ 's balance sheet in the $(\ell, b)$ plane is that of an unbiased random walk around the $45^{\circ}$ line, since only steps away from the origin are possible. Consider a bank $i$ 
after $n$ steps from the origin and let $\ell_{n}$ be the number of liabilities and $b_{n}=n-\ell_{n}$ be the number of assets. Define the event $A_{n}=\left\{b_{n}+b^{0}-c \ell_{n}<0\right\}$ that bank $i$ is ripe for collective foreclosure by its' creditors.

$$
P\left(\left\{A_{n}\right\}\right)=\sum_{\ell>\left(n+b^{0}\right) /(1+c)}\left(\begin{array}{l}
n \\
\ell
\end{array}\right) 2^{-n},
$$

and

$$
\sum_{n=1}^{\infty} P\left(\left\{A_{n}\right\}\right)<+\infty
$$

According to the Borel-Cantelli lemma, the probability that events $A_{n}$ occur an infinite number of times (for an infinite number of indices $n$ ) is zero.

Therefore, the number of times when bank $i$ can fail, asymptotically, is at most finite ${ }^{17}$. Since the rate of failure, in the stationary state, is the number of defaults divided by the interval of time, and the number of defaults is finite as the interval of time diverges, then the rate of default of bank $i$ is zero. This shows that, in the absence of defaults of other banks, a bank has a vanishing rate of default as long as $c<1$. Hence in the limits $n \rightarrow \infty, \lambda \rightarrow 0$ a default free $(\mu=0)$ state is a solution of the Master equation.

In this proof the order of limits is important. Taking $\lambda \rightarrow 0$ with finite $N$ yields the complete graph and the process discussed above cannot be considered a simple random walk when $\ell \sim N$. Second, when $c=1$ the result does not hold. Indeed, when $c=1$ the asymptotic behavior of the model is again related to the properties of unbiased random walks. With $c=1$, however, the random walk spends a finite fraction of its time in the unstable region $b+b^{0}<c \ell$, which means that even in the limit $N \rightarrow \infty$ and $\lambda \rightarrow 0$ all banks will surely default.

${ }^{17}$ Notice that when bank $i$ defaults, it starts again from $n=0$. 


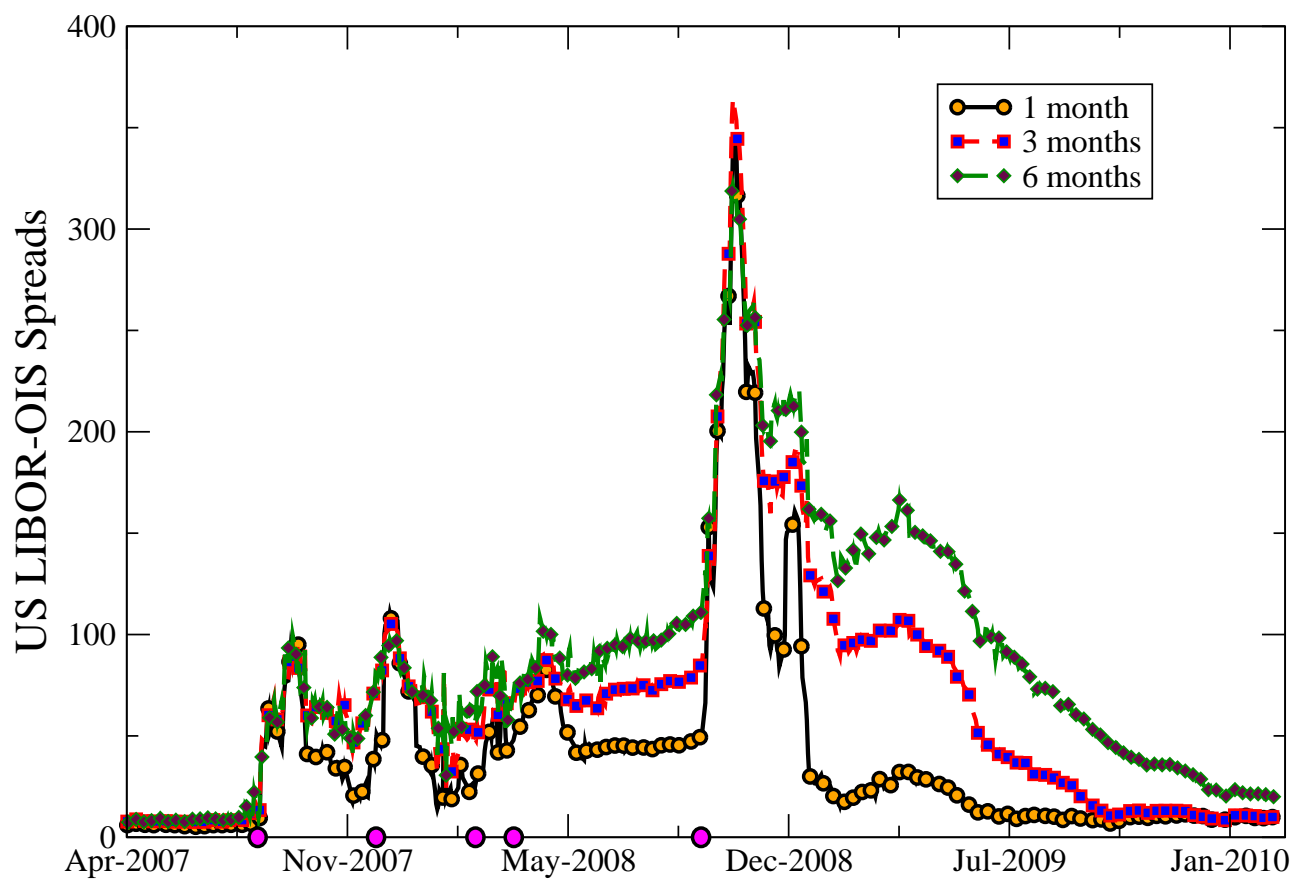

Figure 1: 1 month, 3 month and 6 month US LIBOR-OIS Rates, in basis points, during the financial crisis of 2007-09. The circles on the time-axis highlight events, which on reading from left to right are: (i) August 9, 2007 - BNP Paribas suspends calculation of asset values of three money market funds exposed to US sub-prime mortgages; (ii) November 20, 2007 - Freddie Mac announces losses for the third quarter of 2007; (iii) January 24, 2008 - Société Générale reveals trading losses resulting from fraudulent activities by a single trader; (iv) March 13, 2008 - Bear Stearns files for bankruptcy, and (v) September 15, 2008 - Lehman Brothers files for bankruptcy. 


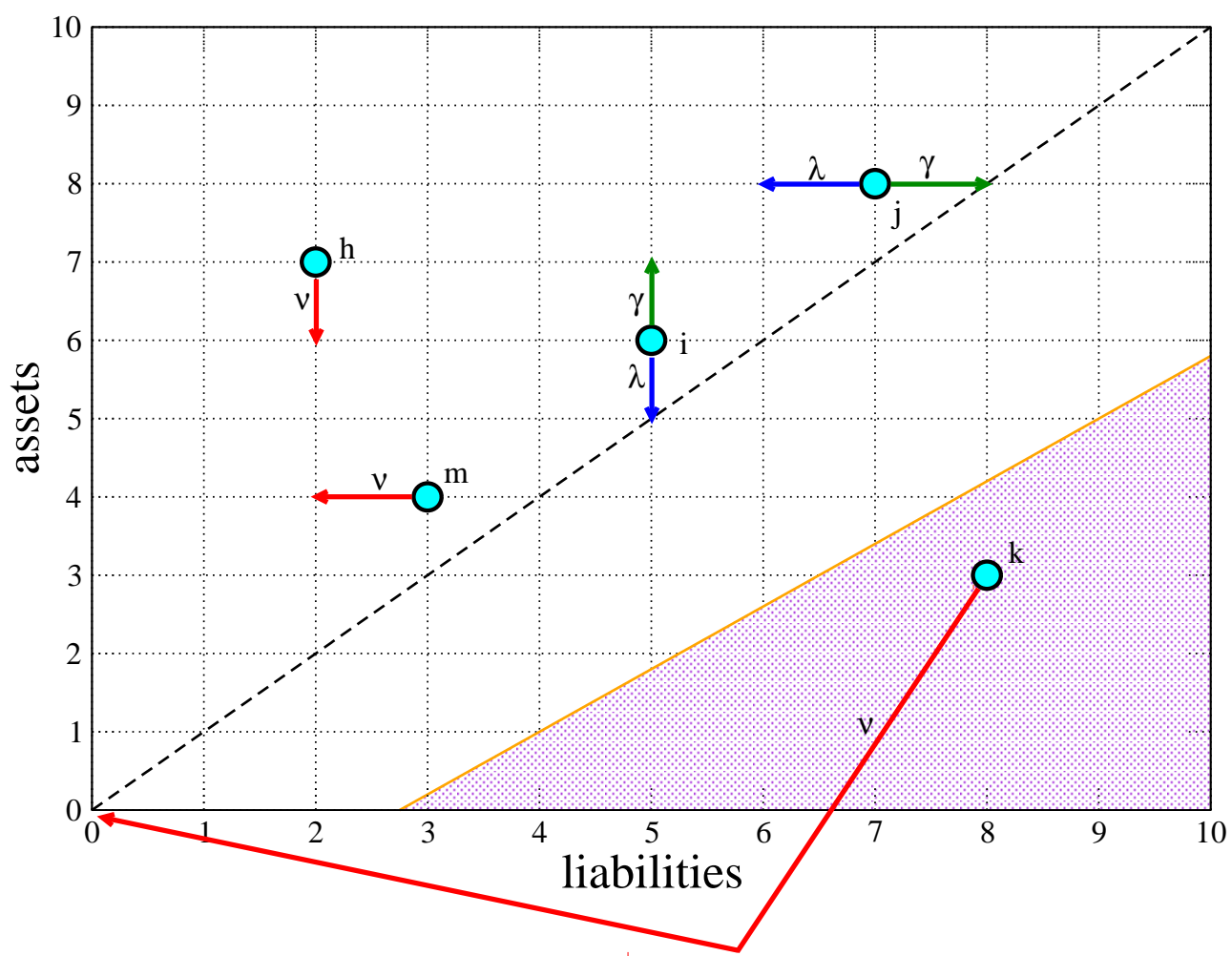

Figure 2: Schematic diagram of elementary processes in the liabilities-assets, $(\ell, b)$, plane during the models' network dynamics. The shaded area correspond to where Eq. (5) is satisfied and foreclosures take place. With rate $\gamma$, a credit relationship $i \rightarrow j$ is established. Bank $i$ gains an assets $\left(b_{i} \rightarrow\right.$ $\left.b_{i}+1\right)$, while $j$ increments the number of liabilities it holds $\left(\ell_{j} \rightarrow \ell_{j}+1\right)$. With rate $\lambda$, however this link matures and expires, causing a rearrangement of balance sheets. Finally, with rate $v$, debtor $k$ reveals its' balance sheet position, $\left(\ell_{k}, b_{k}\right)$ to the creditors. If $k$ is found to be in the shaded region, foreclosures take place and $k$ defaults, thereby transporting it back to the origin, i.e., $\left(\ell_{k}, b_{k}\right) \rightarrow(0,0)$. Bank $m$, who had borrowed from $k$, loses one liability $\left(\ell_{m} \rightarrow \ell_{m}-1\right)$, while Bank $h$ who lent to $k$ loses an asset $\left(b_{h} \rightarrow b_{h}-1\right)$. 


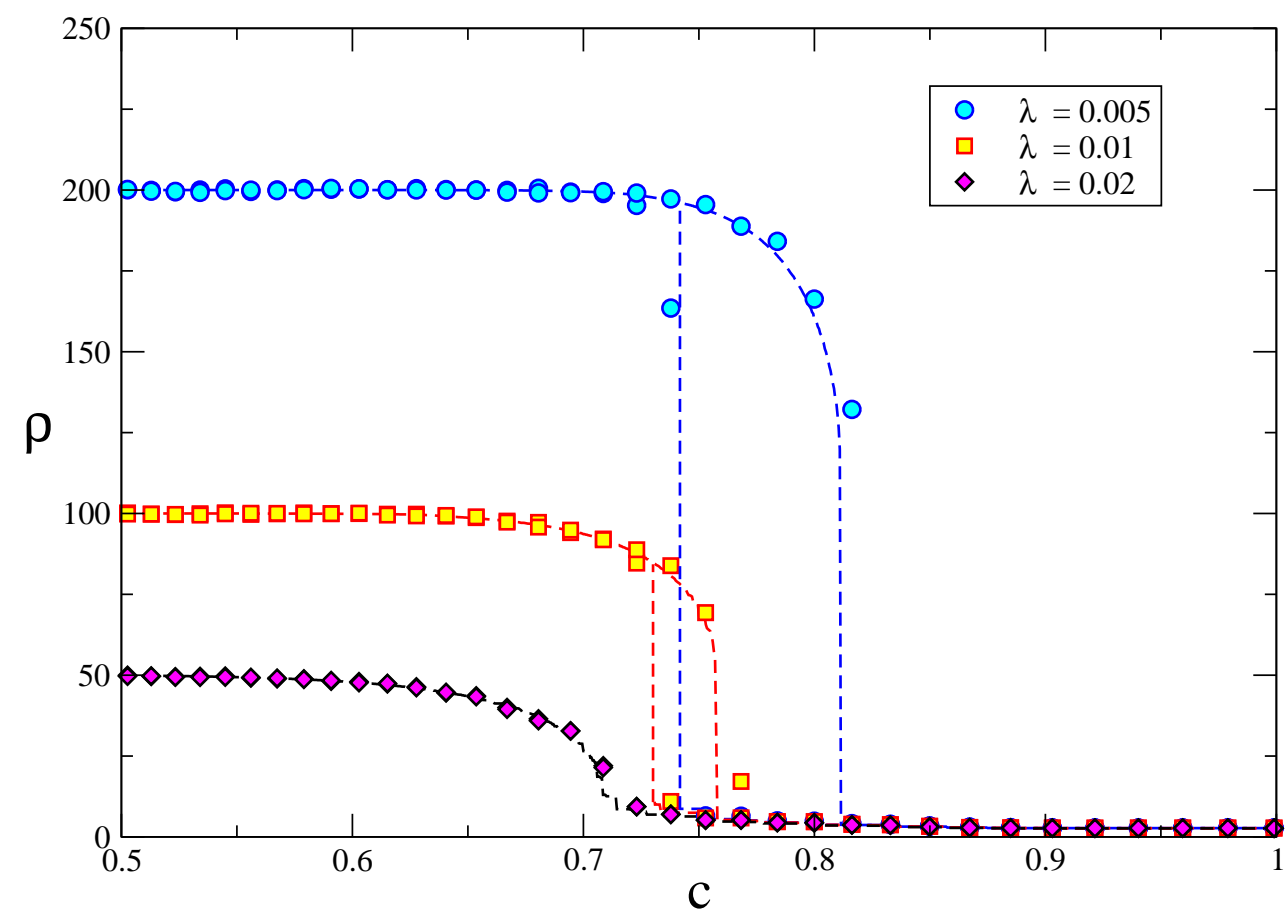

Figure 3: Average density $\rho$ in the network as a function of cost $c$ for different values of $\lambda$. The symbols are produced from direct simulations while the lines are from solving the corresponding master equation, Eq. (6) numerically. In producing the curves we took $v=b^{0}=2.0$ and $N=2000$. 


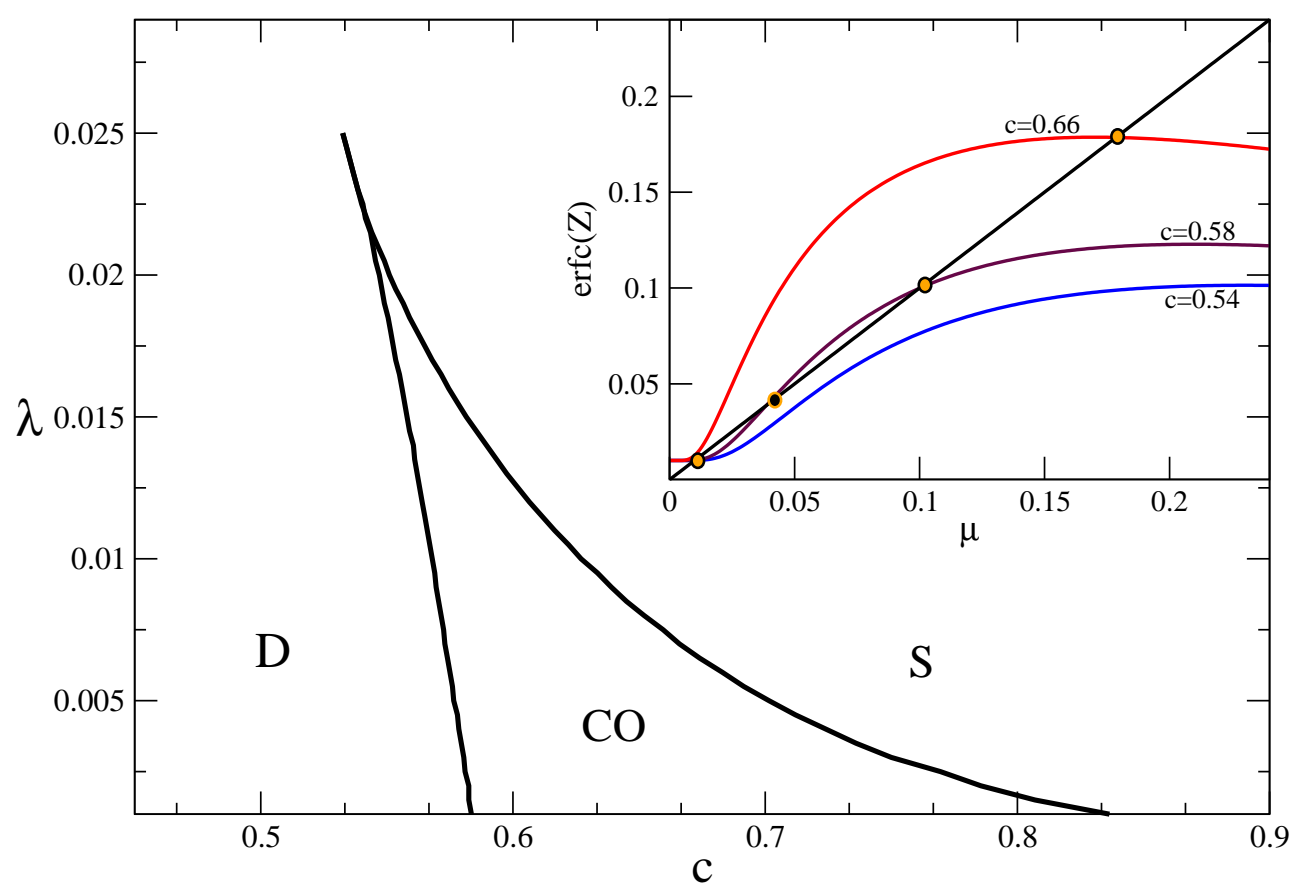

Figure 4: Phase diagram in the $c$ vs. $\lambda$ plane, where the boundaries distinguishes the set of parameters that result in either a dense (D) or sparse (S) network. In producing the curves we took $v=b^{0}=2.0$. We also note that for small $\lambda$, there is a third phase of co-existence (CO) between the dense and sparse states. In the Insert we plot $\operatorname{erfc}(Z)$ as a function of $\mu$, for $\lambda=0.01$, where $Z$ is given by Eq. (9). The different curves correspond to different $c$ values. We note the existence of either one or three fixed points. 


\section{References}

Adrian, T., Shin, H. S., 2010. The changing nature of financial intermediation and the financial crisis of 2007-2009. Annual Review of Economics 2, pp. 603-618.

Acharya, V., Gale, D., Yorulmazer, T., 2011. Rollover risk and market freezes. Journal of Finance 66(4), pp. 1177-1209.

Albert, R., Jeong, H., Barabasi, A. L., 2000. Error and attack tolerance of complex networks. Nature 406(6794), 378-382.

Afonso, G. M., Shin, H. S., 2011. Precautionary demand and liquidity in payment systems. Journal of Money, Credit, and Banking, forthcoming.

Allen, F., Babus A., 2009. Networks in finance, in: Kleindorfer, P., Wind, J. (Eds.) The network challenge: strategy, profit, and risk in an interlinked world. Wharton School Publishing, pp. 367-382.

Allen, F., Babus A., Carletti, E., 2010. Asset commonality, debt maturity and systemic risk. Working paper no. 10-30, Wharton Financial Institutions Center, University of Pennsylvania.

Allen, F., Gale, D., 2000. Financial contagion. Journal of Political Economy 108(1), pp. 1-33.

Bech, M. L., Atalay, E., 2010. The topology of the federal funds market. Physica A: Statistical Mechanics and its Applications 389(22), pp. 5223-5246.

Brunnermeier, M. K., Oehmke, M., 2010. The maturity rat race. Working paper no. 16607, National Bureau of Economic Research.

Caballero, R. J., Simsek, A., 2009. Complexity and financial panics. Working paper no. 09-17, MIT Department of Economics.

Caruana, J., 2009. The international policy response to financial crises: making the macroprudential approach operational. Retrieved from Bank for International Settlements: www.bis.org/speeches/sp090911.htm.

Cross, M., Fisher, P., Weeken, O., 2010. The bank's balance sheet during the crisis. Bank of England Quarterly Bulletin 2010(Q1), pp.34-42.

Diamond D.W., Rajan, R.G., 2011. Fear of fire sales, illiquidity seeking, and credit freezes. The Quarterly Journal of Economics 126 (2), pp. 557-591. 
Ehrhardt, G.C.M.A., Marsili, M., 2006. Phenomenological models of socioeconomic network dynamics. Physical Review E 74(3), 036106.

Frankel, D. M., Morris, S., Pauzner, A. Equilibrium selection in global games with strategic complementarities. Journal of Economic Theory 108(1), pp. 1-44.

Gai, P., Kapadia, S., 2010. Contagion in financial networks. Proceedings of the Royal Society A 466(2120), pp. 2401-2423.

Gai, P., Haldane, A., Kapadia, S., 2011. Complexity, concentration and contagion. Journal of Monetary Economics 58, forthcoming.

Gardiner, C., 2009. Stochastic methods: a handbook for the natural and social sciences, 4th ed. Springer-Verlag, Berlin.

Giesecke, K., Weber, S., 2006. Credit contagion and aggregate losses. Journal of Economic Dynamics and Control 30(5), pp. 741-767.

Haldane, A., 2009. Rethinking the financial network. Retrieved from Bank of England: www.bankofengland.co.uk/publications/speeches/2009/speech386.pdf.

Hatchett, J. P. L., Kühn, R., 2009. Credit contagion and credit risk. Quantitative Finance 9(4), pp. 373-382.

He, Z., Xiong, W., 2011. Dynamic debt runs. Review of Financial Studies, forthcoming.

Jackson, M.O., 2008. Social and economic networks. Princeton University Press, Princeton.

May, R. M., Levin, S. A., Sugihara, G., 2008. Complex systems: ecology for bankers. Nature 451(7181), pp. 893-895.

May, R.M., Arinaminpathy, N., 2010. Systemic risk: the dynamics of model banking systems. Journal of the Royal Society Interface. 7(46), pp. 828-838.

Morris, S., Shin, H. S., 1998. Unique equilibrium in a model of self-fulfilling currency attacks. American Economic Review 88(3), pp. 587-597.

Morris, S., Shin, H. S., 2003. Global games: theory and applications, in: Dewatripont, M., Hansen, L.P., Turnovsky, S. J. (Eds.), Advances in economics and econometrics, the eighth world congress. Cambridge University Press, Cambridge, pp. 56-114. 
Morris, S., Shin, H. S., 2008. Financial regulation in a system context, in Elmendorf, D.W., Mankiw, N.G., Summers, L.H (Eds.), Brookings papers on economic activity. Brookings Institute Press, Washington, DC.

Nier, E., Yang, J., Yorulmazer, T., Alentorn, A., 2007. Network models and financial stability. Journal of Economic Dynamics and Control 31(1), pp 2033-2060.

Pritsker, M., 2009. Knightian uncertainty and interbank lending. working paper, Board of Governors of the Federal Reserve System.

Schweitzer, F., Fagiolo, G., Sornette, D., Vega-Redondo, F., Vespignani, A, White, D. R., 2009. Economic networks: The new challenges. Science 325(5939), pp. 422.

Squam Lake Working Group on Financial Regulation., 2009. Reforming capital requirements for financial institutions. Author:, Washington, DC.

Tucker, P., 2009. The debate on financial system resilience macroprudential instruments. Retrieved from Bank of England: www.bankofengland.co.uk/publications/speeches/2009/speech407.pdf. 


\section{SFB 649 Discussion Paper Series 2011}

For a complete list of Discussion Papers published by the SFB 649, please visit http://sfb649. wiwi. hu-berlin.de.

001 "Localising temperature risk" by Wolfgang Karl Härdle, Brenda López Cabrera, Ostap Okhrin and Weining Wang, January 2011.

002 "A Confidence Corridor for Sparse Longitudinal Data Curves" by Shuzhuan Zheng, Lijian Yang and Wolfgang Karl Härdle, January 2011.

003 "Mean Volatility Regressions" by Lu Lin, Feng Li, Lixing Zhu and Wolfgang Karl Härdle, J anuary 2011.

004 "A Confidence Corridor for Expectile Functions" by Esra Akdeniz Duran, Mengmeng Guo and Wolfgang Karl Härdle, January 2011.

005 "Local Quantile Regression" by Wolfgang Karl Härdle, Vladimir Spokoiny and Weining Wang, January 2011.

006 "Sticky Information and Determinacy" by Alexander Meyer-Gohde, January 2011.

007 "Mean-Variance Cointegration and the Expectations Hypothesis" by Till Strohsal and Enzo Weber, February 2011.

008 "Monetary Policy, Trend Inflation and Inflation Persistence" by Fang Yao, February 2011.

009 "Exclusion in the All-Pay Auction: An Experimental Investigation" by Dietmar Fehr and Julia Schmid, February 2011.

010 "Unwillingness to Pay for Privacy: A Field Experiment" by Alastair R. Beresford, Dorothea Kübler and Sören Preibusch, February 2011.

011 "Human Capital Formation on Skill-Specific Labor Markets" by Runli Xie, February 2011.

012 "A strategic mediator who is biased into the same direction as the expert can improve information transmission" by Lydia Mechtenberg and J ohannes Münster, March 2011.

013 "Spatial Risk Premium on Weather Derivatives and Hedging Weather Exposure in Electricity" by Wolfgang Karl Härdle and Maria Osipenko, March 2011.

014 "Difference based Ridge and Liu type Estimators in Semiparametric Regression Models" by Esra Akdeniz Duran, Wolfgang Karl Härdle and Maria Osipenko, March 2011.

015 "Short-Term Herding of Institutional Traders: New Evidence from the German Stock Market" by Stephanie Kremer and Dieter Nautz, March 2011.

016 "Oracally Efficient Two-Step Estimation of Generalized Additive Model" by Rong Liu, Lijian Yang and Wolfgang Karl Härdle, March 2011.

017 "The Law of Attraction: Bilateral Search and Horizontal Heterogeneity" by Dirk Hofmann and Salmai Qari, March 2011.

018 "Can crop yield risk be globally diversified?" by Xiaoliang Liu, Wei Xu and Martin Odening, March 2011.

019 "What Drives the Relationship Between Inflation and Price Dispersion? Market Power vs. Price Rigidity" by Sascha Becker, March 2011.

020 "How Computational Statistics Became the Backbone of Modern Data Science" by James E. Gentle, Wolfgang Härdle and Yuichi Mori, May 2011.

021 "Customer Reactions in Out-of-Stock Situations - Do promotion-induced phantom positions alleviate the similarity substitution hypothesis?" by Jana Luisa Diels and Nicole Wiebach, May 2011.

\section{SFB 649, Spandauer Str. 1, D-10178 Berlin http:/ / sfb649.wiwi.hu-berlin.de}

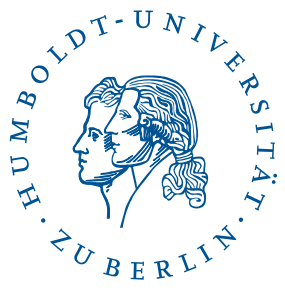




\section{SFB 649 Discussion Paper Series 2011}

For a complete list of Discussion Papers published by the SFB 649, please visit http://sfb649. wiwi. hu-berlin.de.

022 "Extreme value models in a conditional duration intensity framework" by Rodrigo Herrera and Bernhard Schipp, May 2011.

023 "Forecasting Corporate Distress in the Asian and Pacific Region" by Russ Moro, Wolfgang Härdle, Saeideh Aliakbari and Linda Hoffmann, May 2011.

024 "Identifying the Effect of Temporal Work Flexibility on Parental Time with Children" by Juliane Scheffel, May 2011.

025 "How do Unusual Working Schedules Affect Social Life?" by Juliane Scheffel, May 2011.

026 "Compensation of Unusual Working Schedules" by Juliane Scheffel, May 2011.

027 "Estimation of the characteristics of a Lévy process observed at arbitrary frequency" by Johanna Kappus and Markus Reiß, May 2011.

028 "Asymptotic equivalence and sufficiency for volatility estimation under microstructure noise" by Markus Reiß, May 2011.

029 "Pointwise adaptive estimation for quantile regression" by Markus Reiß, Yves Rozenholc and Charles A. Cuenod, May 2011.

030 "Developing web-based tools for the teaching of statistics: Our Wikis and the German Wikipedia" by Sigbert Klinke, May 2011.

031 "What Explains the German Labor Market Miracle in the Great Recession?" by Michael C. Burda and Jennifer Hunt, June 2011.

032 "The information content of central bank interest rate projections: Evidence from New Zealand" by Gunda-Alexandra Detmers and Dieter Nautz, J une 2011.

033 "Asymptotics of Asynchronicity" by Markus Bibinger, J une 2011.

034 "An estimator for the quadratic covariation of asynchronously observed Itô processes with noise: Asymptotic distribution theory" by Markus Bibinger, J une 2011.

035 "The economics of TARGET2 balances" by Ulrich Bindseil and Philipp J ohann König, June 2011.

036 "An Indicator for National Systems of Innovation - Methodology and Application to 17 Industrialized Countries" by Heike Belitz, Marius Clemens, Christian von Hirschhausen, Jens Schmidt-Ehmcke, Axel Werwatz and Petra Zloczysti, June 2011.

037 "Neurobiology of value integration: When value impacts valuation" by Soyoung Q. Park, Thorsten Kahnt, Jörg Rieskamp and Hauke R. Heekeren, June 2011.

038 "The Neural Basis of Following Advice" by Guido Biele, Jörg Rieskamp, Lea K. Krugel and Hauke R. Heekeren, J une 2011.

039 "The Persistence of "Bad" Precedents and the Need for Communication: A Coordination Experiment" by Dietmar Fehr, June 2011.

040 "News-driven Business Cycles in SVARs" by Patrick Bunk, July 2011.

041 "The Basel III framework for liquidity standards and monetary policy implementation" by Ulrich Bindseil and Jeroen Lamoot, J uly 2011.

042 "Pollution permits, Strategic Trading and Dynamic Technology Adoption" by Santiago Moreno-Bromberg and Luca Taschini, July 2011.

043 "CRRA Utility Maximization under Risk Constraints" by Santiago MorenoBromberg, Traian A. Pirvu and Anthony Réveillac, July 2011.

\section{SFB 649, Spandauer Str. 1, D-10178 Berlin http:/ / sfb649.wiwi.hu-berlin.de}

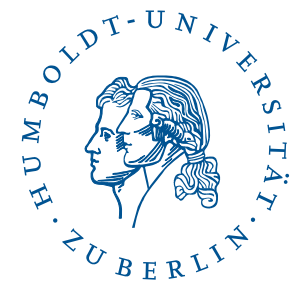




\section{SFB 649 Discussion Paper Series 2011}

For a complete list of Discussion Papers published by the SFB 649, please visit http://sfb649. wiwi. hu-berlin.de.

044 "Predicting Bid-Ask Spreads Using Long Memory Autoregressive Conditional Poisson Models" by Axel Groß-Klußmann and Nikolaus Hautsch, July 2011.

045 "Bayesian Networks and Sex-related Homicides" by Stephan Stahlschmidt, Helmut Tausendteufel and Wolfgang K. Härdle, July 2011.

046 "The Regulation of Interdependent Markets", by Raffaele Fiocco and Carlo Scarpa, July 2011.

047 "Bargaining and Collusion in a Regulatory Model", by Raffaele Fiocco and Mario Gilli, July 2011.

048 "Large Vector Auto Regressions", by Song Song and Peter J. Bickel, August 2011.

049 "Monetary Policy, Determinacy, and the Natural Rate Hypothesis", by Alexander Meyer-Gohde, August 2011.

050 "The impact of context and promotion on consumer responses and preferences in out-of-stock situations", by Nicole Wiebach and Jana L. Diels, August 2011.

051 "A Network Model of Financial System Resilience", by Kartik Anand, Prasanna Gai, Sujit Kapadia, Simon Brennan and Matthew Willison, August 2011.

052 "Rollover risk, network structure and systemic financial crises", by Kartik Anand, Prasanna Gai and Matteo Marsili, August 2011. 